\title{
Cause of death in hospitalized patients with laboratory-confirmed influenza
}

\author{
Causa de muerte en pacientes hospitalizados \\ con gripe confirmada por laboratorio
}

\author{
I. Casado ${ }^{1}$, I. Martínez-Baz ${ }^{1,2}$, Y. Floristán ${ }^{1,2}$, J. Chamorro ${ }^{3}$, C. Ezpeleta ${ }^{3}$, J. Castilla ${ }^{1,2}$ \\ and the Network for Influenza Surveillance in Hospitals of Navarra
}

\begin{abstract}
Background. We analyzed the underlying cause of death recorded in hospitalized patients with laboratory-confirmed influenza.

Methods. The present study included all patients with a laboratory-confirmed diagnosis of influenza during the influenza seasons 2009-2010 to 2013-2014 who were attended to in hospital and died. Their underlying cause of death according to the International Classification of Diseases 10th Revision was obtained from the Navarre Mortality Registry.
\end{abstract}

Results. Among 49 patients studied, the underlying causes of death were $35 \%$ influenza, $4 \%$ pneumonia, $14 \%$ other respiratory diseases, $10 \%$ circulatory disease and $37 \%$ other causes.

Conclusions. Non-cardiorespiratory causes accounted for a third of deaths in patients with confirmed influenza, thus all-cause mortality should be considered in estimating the full burden of influenza mortality.

Keywords. Cause of death. Death certificate. Influenza. Influenza-like illness. Mortality.

\section{RESUMEN}

Fundamento. La mortalidad por gripe no se conoce bien porque la mayoría de las personas que mueren por gripe no se confirman por laboratorio. Analizamos la causa básica de muerte registrada en los pacientes hospitalizados con gripe confirmada por laboratorio.

Métodos. Se incluyeron todos los pacientes con diagnóstico de gripe por laboratorio que habían sido atendidos en el hospital y murieron durante las temporadas 2009-2010 a 2013-2014 en Navarra. La causa básica de muerte se obtuvo del Registro de Mortalidad.

Resultados. Entre los 49 pacientes estudiados, la causa básica de muerte fue en el $35 \%$ gripe, en el $4 \%$ neumonía en el $14 \%$ otras enfermedades respiratorias, en el $10 \%$ enfermedades cardiovasculares y en el $37 \%$ otras causas.

Conclusiones. Un tercio de las muertes en pacientes con gripe confirmada se asignaron a causas no cardiorrespiratorias. Deberían tenerse en cuenta todas las causas para estimar la carga total de la mortalidad por gripe.

Palabras clave. Causa de muerte. Certificado de defunción. Gripe. Síndrome gripal. Mortalidad.
1. Instituto de Salud Pública de Navarra. Instituto de Investigación Sanitaria de Navarra (IdiSNA). Pamplona. Spain.

2. CIBER de Epidemiología y Salud Pública (CIBERESP). Spain.

3. Complejo Hospitalario de Navarra. Instituto de Investigación Sanitaria de Navarra (IdiSNA). Pamplona. Spain.

Recepción: 12 de febrero de 2015 Aceptación provisional: 31 de marzo de 2015 Aceptación definitiva: 20 de abril de 2015

\section{Correspondencia:}

Jesús Castilla

Instituto de Salud Pública de Navarra

C/ Leyre 15

31003 Pamplona, Spain

Email: jcastilc@navarra.es

Funding. This study was funded by the Carlos III Institute of Health (PS12/00087), and by the I-MOVE program of the European Center for Disease Prevention and Control (ECDC).

Conflicts of interests. The authors declare no conflict of interest. 


\section{INTRODUCTION}

Influenza virus circulation is usually associated with increased mortality in populations ${ }^{1}$. Influenza-related deaths mainly affect persons with major chronic conditions $^{2}$, and these comorbidities tend to prevail as the underlying cause in death certificates $^{3}$. As most influenza cases are not laboratory tested, the actual impact of influenza on mortality is not well known. Different approaches have been used to estimate the burden of mortality caused by influenza: considering excess all-cause mortality or specific causes such as influenza and pneumonia, or respiratory and cardiovascular diseases ${ }^{4-7}$. This study analyzed the underlying cause of death recorded in hospitalized patients with laboratory-confirmed influenza.

\section{METHODS}

The study was conducted in the region of Navarra, Spain, with around 640,000 inhabitants. The Navarra Ethical Committee for Medical Research approved the study protocol. A high standard of patient confidentiality was maintained.

All the six general hospitals of the region were included in the study. Influenza surveillance in hospitals was based on protocol, which specified early detection and nasopharyngeal and pharyngeal swabbing of all hospitalized patients with influenza-like illness, considered to be the sudden onset of any general symptom (fever or feverishness, malaise, headache or myalgia) in addition to any respiratory symptom (cough, sore throat or shortness of breath). The request for the influenza test was available to all hospital physicians. Swabs were processed by real-time reverse-transcription polymerase-chain-reaction assay in two laboratories in the region (Complejo Hospitalario de Navarra and Clínica Universidad de Navarra), and samples positive for influenza $\mathrm{A}(\mathrm{H} 1 \mathrm{~N} 1) \mathrm{pdm} 09, \mathrm{~A}(\mathrm{H} 3 \mathrm{~N} 2)$ and $B$ viruses were identified.

The departments of clinical microbiology and preventive medicine of the hospitals participated in the active search and reporting of all influenza positive patients.
The vital status of influenza positive patients was evaluated at hospital discharge and 30 days after the diagnosis.

The present analysis included all patients with a laboratory-confirmed diagnosis of influenza during the influenza seasons 2009-2010 to 2013-2014 who were attended in hospital and died during the hospital admission or in the 30 days following the diagnosis of influenza. Their underlying cause of death according to the International Classification of Diseases 10th Revision (ICD-10) was obtained from the Navarra Mortality Registry, and was classified in the following categories: influenza (codes J09-J11), pneumonia (codes J12-J18), other respiratory diseases (codes J00-J08 and J19-J99), circulatory diseases (codes I00-I99), malignant neoplasms (codes C00-C97) and other causes (rest of the codes). The non-underlying causes of death derived from the death certificate were explored as a complementary analysis.

From the electronic healthcare records, we obtained the following baseline variables: sex, age, major chronic conditions (heart disease, lung disease, renal disease, cancer, diabetes mellitus, cirrhosis, dementia, stroke, immunodeficiency, rheumatic disease and body mass index $\geq 40 \mathrm{~kg} / \mathrm{m}^{2}$ ), influenza vaccination in the corresponding season, and admission diagnosis categorized as severe acute respiratory illness, exacerbation of a chronic condition attributable to influenza, and other reasons. A descriptive analysis was made of the characteristics of the cases included and the distribution of causes of death. The two-tailed Fisher's exact test and Chi-square test were used to compare categorical variables.

\section{RESULTS}

Over the study period, a total of 2852 patients hospitalized with influenza-like illness were swabbed, 737 (26\%) were laboratory-confirmed for influenza, and among them, 49 (7\%) died. The six general hospitals of the region reported laboratory-confirmed cases and five of them reported deaths among influenza cases. Five to nine deaths were recorded for each influenza 
Table 1. Association between selected variables and influenza coded as the underlying cause of death in patients who died with laboratory-confirmed influenza

\begin{tabular}{|c|c|c|c|}
\hline & Total & Influenza coded & 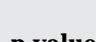 \\
\hline & $\mathbf{n}$ & n (\%) & p value \\
\hline Sex & & & 1.000 \\
\hline Male & 21 & $7(33)$ & \\
\hline Female & 28 & $10(36)$ & \\
\hline Age groups (years) & & & 0.351 \\
\hline$<65$ & 17 & $8(47)$ & \\
\hline $65-84$ & 17 & $4(24)$ & \\
\hline$\geq 85$ & 15 & $5(33)$ & \\
\hline Major chronic conditions & & & 0.015 \\
\hline No & 6 & $5(83)$ & \\
\hline Yes & 43 & $12(28)$ & \\
\hline Vaccination status & & & 0.549 \\
\hline No & 28 & $11(39)$ & \\
\hline Yes & 21 & $6(29)$ & \\
\hline Hospital admission diagnosis & & & $0.009^{\mathrm{a}}$ \\
\hline Severe acute respiratory illness & 38 & $17(45)$ & \\
\hline Exacerbation of a chronic condition & 6 & $0(0)$ & \\
\hline Other & 5 & $0(0)$ & \\
\hline Influenza virus type/subtype & & & $0.082^{\mathrm{b}}$ \\
\hline $\mathrm{A}(\mathrm{H} 1 \mathrm{N1}) \mathrm{pdm} 09$ & 23 & $11(48)$ & \\
\hline $\mathrm{A}(\mathrm{H} 3 \mathrm{~N} 2)$ & 23 & $6(26)$ & \\
\hline $\mathrm{B}$ & 3 & $0(0)$ & \\
\hline Time interval diagnosis-death (days) & & & 0.564 \\
\hline$<7$ & 26 & $8(31)$ & \\
\hline$\geq 7$ & 23 & $9(39)$ & \\
\hline Season & & & NA \\
\hline 2009-2010 & 5 & $2(40)$ & \\
\hline 2010-2011 & 7 & $4(57)$ & \\
\hline 2011-2012 & 6 & $1(17)$ & \\
\hline 2012-2013 & 9 & $3(33)$ & \\
\hline 2013-2014 & 22 & $7(32)$ & \\
\hline Total & 49 & 17 (35) & \\
\hline
\end{tabular}

NA: not available

${ }^{a}$ Comparison between patients admitted with severe acute respiratory illness versus the other two categories.

${ }^{\text {b }}$ Comparison between patients with influenza A(H1N1)pdm09 virus and other subtypes identified.

season studied, except for season 20132014 , in which 22 deaths (45\%) were included. Among all studied patients, 28 (57\%) were women, median age was 76 years (range 28-97 years), 43 (88\%) had a major chronic condition, and 21 (43\%) had been vaccinated in the corresponding influenza season. The admission diagnosis was severe acute respiratory illness in 38 patients (78\%), exacerbation of a chronic condition in 6 patients (12\%), and other admission diagnoses (scheduled admission for surgery or treatment, urinary sepsis, gastroenteritis and cancer complications) in the remaining patients $(10 \%)$. Influenza virus subtype $\mathrm{A}(\mathrm{H} 1 \mathrm{~N} 1) \mathrm{pdm} 09$ was detected in 23 patients, $\mathrm{A}(\mathrm{H} 3 \mathrm{~N} 2)$ in 23 , and $\mathrm{B}$ in 3 . The median time between diagnosis and death was 6 days (range $0-51$ days) (Table 1 ). Influenza coded as the underlying cause of death was less frequent in patients with major chronic conditions ( $83 \%$ vs. $28 \%$; $\mathrm{p}=0.015$ ). 
Among patients admitted with severe acute respiratory illness, $45 \%(17 / 38)$ were coded with influenza as the underlying cause of death versus none of those admitted with other diagnoses $(\mathrm{p}=0.009)$ (Table 1$)$.

Influenza was coded as the underlying cause of death in $35 \%$ of patients (17/49), pneumonia in $4 \%(2 / 49)$, other respiratory cause in $14 \%$ (7/49), circulatory diseases in $10 \%(5 / 49)$, malignant neoplasms in $16 \%$ (8/49), and all other causes of death in $20 \%$ (10/49) (Fig.1).

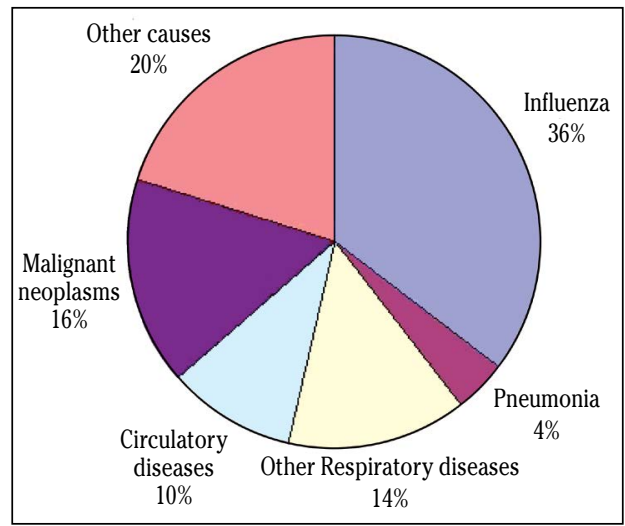

Figure 1. Percentage distribution of causes of death in hospitalized patients with laboratory-confirmed influenza in Navarra, Spain, influenza seasons 2009-2010 to 2013-2014 $(n=49)$
Distribution of cause of death was evaluated in 2013-2014 season and in other seasons separately, and no differences were appreciated with respect to the total. By virus type/subtype, influenza was coded in $48 \%(11 / 23)$ of patients with a confirmed diagnosis for $\mathrm{A}(\mathrm{H} 1 \mathrm{~N} 1) \mathrm{pdm} 09$ virus, in $26 \%$ $(6 / 23)$ in those confirmed for influenza A(H3N2) and in none of three confirmed for influenza B. Thirty-eight deaths were in patients admitted with severe acute respiratory illness, and $45 \%$ of them were coded with influenza as the underlying cause of death, $5 \%$ with pneumonia, $18 \%$ with other respiratory diseases, $5 \%$ with circulatory diseases, $13 \%$ with neoplasms, and 13\% with other causes of death (Table 2).

Information on non-underlying causes of death was available for $37(76 \%)$ patients, and in two of them influenza was coded as a cause, resulting in a total of 19 (39\%) patients with influenza coded as any cause of death.

\section{DISCUSSION}

In this study we analyze the underlying cause of death coded in hospitalized patients who died with a laboratory-confirmed diagnosis of influenza. Influenza was coded as the underlying cause of death in

Table 2. Underlying cause of death in patients with laboratory-confirmed influenza by virus subtype, hospital admission diagnosis and influenza season

\begin{tabular}{|c|c|c|c|c|c|c|c|c|c|}
\hline \multirow{3}{*}{ Cause of death } & \multirow[b]{2}{*}{ Total } & \multicolumn{3}{|c|}{ Virus type/subtype } & \multicolumn{3}{|c|}{ Hospital admission diagnosis } & \multicolumn{2}{|c|}{ Influenza season } \\
\hline & & $\begin{array}{l}\text { A(H1N1) } \\
\text { pdm09 }\end{array}$ & A(H3N2) & B & $\begin{array}{c}\text { Severe acute } \\
\text { respiratory } \\
\text { illness }\end{array}$ & $\begin{array}{l}\text { Exacerbation } \\
\text { of chronic } \\
\text { condition }\end{array}$ & Other & $\begin{array}{c}2009-2010 \\
\text { to } \\
2012-2013\end{array}$ & $\begin{array}{l}2013- \\
2014\end{array}$ \\
\hline & $\mathbf{n}(\%)$ & $\mathbf{n}(\%)$ & n (\%) & n (\%) & n (\%) & n (\%) & n (\%) & $\mathbf{n}(\%)$ & n (\%) \\
\hline Influenza & $17(35)$ & $11(48)$ & $6(26)$ & $0(0)$ & $17(45)$ & $0(0)$ & $0(0)$ & $10(37)$ & $7(32)$ \\
\hline Pneumonia & $2(4)$ & $0(0)$ & $1(4)$ & $1(33)$ & $2(5)$ & $0(0)$ & $0(0)$ & $1(4)$ & $1(5)$ \\
\hline $\begin{array}{l}\text { Other respiratory } \\
\text { diseases }\end{array}$ & $7(14)$ & $1(4)$ & $6(26)$ & $0(0)$ & $7(18)$ & $0(0)$ & $0(0)$ & $3(11)$ & $4(18)$ \\
\hline $\begin{array}{l}\text { Circulatory } \\
\text { diseases }\end{array}$ & $5(10)$ & $3(13)$ & $1(4)$ & $1(33)$ & $2(5)$ & $2(33)$ & $1(20)$ & $5(19)$ & $0(0)$ \\
\hline $\begin{array}{l}\text { Malignant } \\
\text { neoplasms }\end{array}$ & $8(16)$ & $5(22)$ & $2(9)$ & $1(33)$ & $5(13)$ & $1(17)$ & $2(40)$ & $5(19)$ & $3(14)$ \\
\hline Other causes & $10(20)$ & $3(13)$ & $7(30)$ & $0(0)$ & $5(13)$ & $3(50)$ & $2(40)$ & $3(11)$ & $7(32)$ \\
\hline Total & $49(100)$ & $23(100)$ & $23(100)$ & $3(100)$ & $38(100)$ & $6(100)$ & $5(100)$ & $27(100)$ & $22(100)$ \\
\hline
\end{tabular}


$35 \%$ of the cases, and this percentage was lower in patients with major chronic conditions. Only $53 \%$ of deaths were due to respiratory causes, a percentage that rose to $63 \%$ if both respiratory and cardiovascular diseases were included. In a similar analysis Mustacello et al. found $47 \%$ and $80 \%$ of deaths, respectively ${ }^{8}$. Considering multiple causes of death, underlying and non-underlying, the proportion of influenza coded as a cause of death reached $39 \%$ of all influenza-related mortality.

The number of deaths included in the study notably increased in the 2013-2014 influenza season. This finding can be explained by the sum of several factors: in this season influenza $\mathrm{A}(\mathrm{H} 3 \mathrm{~N} 2)$ and $\mathrm{A}(\mathrm{H} 1 \mathrm{~N} 1) \mathrm{pdm} 09$ viruses co circulated and presented several relevant mutations, the influenza vaccine effectiveness was low, several outbreaks were detected in nursing homes and long term care facilities affecting high risk persons ${ }^{9}$, and lastly, although the protocol for influenza in hospitals remained unchanged, some improvements in the detection of hospitalized patients with influenza were also possible. Nevertheless, the distribution of cause of death among patients who died with laboratory-confirmed influenza was not different between the 2013-2014 season and the four previous influenza seasons.

These results are the average of five influenza seasons with cases due to different virus types and subtypes. Although the influenza test is available for all hospital physicians, most persons dying from influenza-related causes are probably not tested, and without a laboratory-confirmed test they are less likely to be coded as influenza. Therefore in this study the proportion of deaths coded as influenza may be overestimated.

As observed in previous studies, a virological diagnosis of influenza does not necessarily mean that influenza is recorded as the underlying cause of death, thus underestimating influenza burden in the Statistics of Causes of Death ${ }^{8,10,11}$. Influenza can trigger secondary bacterial infections or exacerbate existing chronic conditions, and these comorbidities usually prevail as the underlying cause of death. The burden of influenza-related mortality has usually been estimated based on the excess mortality from influenza and pneumonia, and the Centers for Diseases Control and Prevention have proposed extending these estimates to include excess deaths from all respiratory and cardiovascular diseases ${ }^{4}$. According to our results, $37 \%$ of the mortality in patients with laboratory-confirmed influenza would remain uncounted, and would only be identified by including all other causes of death in the analysis. Our study adds to others that support the need to consider all-cause mortality to estimate the total burden of influenza mortality ${ }^{6,11-13}$. These results also suggest the importance of considering allcause deaths to quantify the total effect of the influenza vaccine on mortality.

In conclusion, these results show that influenza coded as any cause of death only represents a small part of all influenza-related mortality. Non-cardiorespiratory causes accounted for a relevant proportion of influenza-related deaths, thus all-cause mortality should be considered to estimate the full burden of influenza mortality.

\section{Acknowledgements}

The members of the Network for Influenza Surveillance in Hospitals of Navarra are: Pilar Artajo, Judith Chamorro, Patricia Fanlo, Mercedes Gabari, Javier Hueto, Carlos Pérez, María Ruiz (Complejo Hospitalario de Navarra); José Javier García Irure, María Teresa Ortega, Montse Torres, Paulino González (Hospital Reina Sofía, Tudela); Francisco Lameiro, Ana Navascués, Laura Barrado (Hospital García Orcoyen, Estella); Mirian Fernández, Gabriel Reina, Jorge Núñez (Clínica Universidad de Navarra); Aurelio Barricarte, Manuel García Cenoz, Marcela Guevara, Fátima Irisarri, Maite Arriazu, Agurtzane Zabala, Jesús Castilla (Instituto de Salud Pública de Navarra).

\section{BIBLIOGRAFIA}

1. GLEZEN WP. Serious morbidity and mortality associated with influenza epidemics. Epidemiol Rev 1982; 4: 25-44. 
2. Pebody RG, Mclean E, Zhao H, Cleary P, BraceBRIDGE S, Foster $\mathrm{K}$ et al. Pandemic Influenza A (H1N1) 2009 and mortality in the United Kingdom: risk factors for death, April 2009 to March 2010. Euro Surveill 2010; 15. pii: 19571.

3. MoRENs DM. Influenza-related mortality: considerations for practice and public health. JAMA 2003; 289: 227-229.

4. Centers for Disease Control and Prevention (CDC). Estimates of deaths associated with seasonal influenza - United States, 19762007. MMWR Morb Mortal Wkly Rep 2010; 59: 1057-1062.

5. Kyncl J, Prochazka B, Goddard NL, Havlickova M, Castkova J, Otavova M et al. A study of excess mortality during influenza epidemics in the Czech Republic,1982-2000. Eur J Epidemiol 2005; 20: 365-371.

6. Simonsen L, Spreeuwenberg P, Lustig R, Taylor RJ, FLEMING DM, KRONEMAn M et al. Global mortality estimates for the 2009 Influenza Pandemic from the GLaMOR project: a modeling study. PLoS Med 2013; 10: e1001558.

7. Thompson WW, Shay DK, Weintraub E, Brammer L, Cox N, Anderson LJ, et al. Mortality associated with influenza and respiratory syncytial virus in the United States. JAMA 2003; 289 : 179-186.
8. Muscatello DJ, Amin J, MacIntyre CR, Newall AT, RAWLinson WD, SinTchenko V et al. Inaccurate ascertainment of morbidity and mortality due to influenza in administrative databases: a population-based record linkage study. PLoS One 2014; 9: e98446.

9. Castilla J, Martínez-Baz I, Navascués A, FernánDez-Alonso M, Reina G, Guevara M et al. Vaccine effectiveness in preventing laboratory-confirmed influenza in Navarre, Spain: 2013/14 mid-season análisis. Euro Surveill 2014/19. pii: 20700.

10. Bancroft EA, LEE S. Use of electronic death certificates for influenza death surveillance. Emerg Infect Dis 2014; 20: 78-82.

11. Pérez-Flores E, IzQuierdo-Puente JC, Castillo-Pérez JJ, Ramírez-Rosales G, Grijalva-Otero I, LóPEZ-MACIAS C et al. Quantifying the mortality caused by the H1N1 influenza virus during the 2009 pandemic in Mexico. J Infect Dev Ctries 2014; 8: 742-748.

12. López-Cuadrado T, de Mateo S, Jiménez-Jorge S, SAVULESCU C, LARRAURI A. Influenza-related mortality in Spain, 1999-2005. Gac Sanit 2012; 26: 325-329.

13. Quandelacy TM, Viboud C, Charu V, Lipsitch M, Goldstein E. Age- and sex-related risk factors for influenza-associated mortality in the United States between 1997-2007. Am J Epidemiol 2014; 179: 156-167. 